\title{
Learning about domestic violence: young people's responses to a Healthy Relationships programme
}

\author{
Jo Bell and Nicky Stanley \\ The University of Hull, UK
}

\begin{abstract}
This paper reports on an evaluation of a drama-based Healthy Relationships programme on domestic violence delivered on a pilot basis to Year 8 pupils. The programme included a play delivered by a local theatre-in-education company followed by a series of weekly workshops. Eighty-five pupils in a secondary school located in an area with high rates of social exclusion participated in the programme and the evaluation. Pupils completed questionnaires immediately before and after the programme and one year after the programme had finished. Thirteen pupils also took part in gendered discussion groups, which considered their views and opinions concerning the play and the workshops. The evaluation indicated that the programme was successful in enhancing pupils' understandings of domestic violence up to one year after delivery. Pupils responded well to the use of drama as a medium for learning, and some young people were able to demonstrate that they had developed positive ideas about healthy relationships. However, there was evidence of uncertainly for some young people with regard to the gendered nature of domestic violence following the programme. The discussion highlights this issue and identifies additional recommendations for both future research and future programmes.
\end{abstract}

\section{Introduction}

Preventive programmes for school children that address the issue of domestic violence have an established history in the United States and Canada (Hague et al., 2001). However, in the United Kingdom their introduction is more recent and patchy. Mullender (2000) found that $84 \%$ of secondary school pupils wanted lessons on domestic violence and what to do about it. She suggested that young people respond positively to learning that employs discussion and drama, and those with personal experience of violence at home need to be facilitated and encouraged to talk to responsive friends and teachers.

This paper outlines the findings of an evaluation of a programme delivered on a pilot basis to 85 Year 8 pupils in a secondary school located in an area with high rates

${ }^{\star}$ Corresponding author. Department of Social Work, The University of Hull, Cottingham Road, Hull HU6 7RX, UK. Email: j.bell@hull.ac.uk

ISSN 1468-1811 (print)/ISSN 1472-0825 (online)/06/030237-14

(C) 2006 Taylor \& Francis

DOI: $10.1080 / 14681810600836356$ 


\section{F. Bell and N. Stanley}

of social exclusion. The school was selected for delivery of the pilot by the domestic violence project that designed and implemented the programme. This project was jointly funded and administered by New Deal for Communities, the local Health Action Zone and the Probation Service.

The programme evaluated here represented the pilot phase of what was planned as an ongoing series of programmes delivered to local schools. The full evaluation, which includes later data from other participating schools, is available separately (see Bell \& Stanley, 2004); the findings reported here provide the basis for further investigation and have informed the development of the programme.

The context in which the programme was delivered and the content of the programme are described briefly. The methodology used for the evaluation is outlined and key findings are presented here. The discussion highlights the positive achievements of the programme at the point of completion and identifies some of the questions that will need to be addressed if such programmes are to be maintained.

\section{Background}

While there are convincing arguments for mainstreaming interventions that encourage the next generation to reject violence and see themselves as having a role in ending it, work on this issue in schools remains in the early stages in the United Kingdom.

A number of education and awareness-raising projects in schools have been piloted and are currently under evaluation (e.g. Thurrock, Bridgend and North Yorkshire). In Scotland, the Zero Tolerance charitable trust has run programmes for schools and youth groups in Edinburgh and Glasgow. In Fife, a play developed in further education toured schools and community centres, reaching almost 2000 young people. The Glasgow and Edinburgh programme was evaluated by independent researchers (Reid Howie Associates Ltd, 2001). The majority of young people participating in the programme in Glasgow and Edinburgh believed that they had learned more about respect, communication, equality, power, violence and abuse. Most of those who watched the play in Fife felt that they had gained new information and learned to know what to do and where to seek help. The majority also felt that school was the best place to explore the issues and wanted to see Zero Tolerance programmes integrated into the school curriculum (Mullender, 2001).

Examples of preventive programmes in schools in the USA and Canada that have been evaluated are provided by Macgowan (1997), Avery-Leaf et al. (1997), Foshee et al. (1998), Jaffe et al. (1992) and Meyer and Stein (2001). According to Meyer and Stein (2001), the most commonly reported significant post-programme difference was that young people increased their knowledge about relationship violence. However, evaluations of these types of programmes tend not to involve any kind of qualitative data that might be able to shed light on the meaning of results. 


\section{The Healthy Relationships programme}

The Healthy Relationships school programme was delivered to Year 8 pupils in a secondary school in a metropolitan area by staff from the domestic violence project in the school year 2001/02. In common with many of the schools in this city, the school chosen for the pilot study has low levels of achievement (6\% of pupils achieved GCSE at grade C or above in 2002). It serves a large local authority housing estate with high indicators of social exclusion, poverty and unemployment. Comprehensive figures for the prevalence of domestic violence in the city are not available, but recent police figures suggest that rates in the area are high, and the domestic violence project was set up initially in response to community concerns relating to safety in the area. The project adopted a holistic approach to tackling domestic violence. This comprised three service strands, including support services for women, perpetrator services for men and the healthy relationships work targeted on young people in local secondary schools.

The programme was designed to help young people recognise domestic violence in order that they might avoid such abuse in future relationships. The aim was to focus on positive behaviour in relationships, exploring issues of gender, power and inequality. The main messages were centred on helping young people develop caring and respectful relationships, in which their first priority would be to look after their own physical and emotional well-being and to recognise destructive signs. The domestic violence project commissioned a local theatre company with experience of theatre-in-education work to deliver a drama production and to collaborate with project staff in developing a series of related interactive workshops.

The issues in the performance and follow-up workshops were chosen to reflect the Personal Health and Social Education requirements of the National Curriculum, which emphasise young people's need to develop social skills, awareness, self-esteem and motivation. The programme also followed guidelines detailed in the National Healthy Schools Standard Guidance document (Department of Education and Employment, 1999), reflecting the themes of safety and sex and relationships education.

The programme was designed by the domestic violence staff member with responsibility for coordinating the educational programme working in collaboration with the theatre company, teaching and health staff from the school, and practitioners from youth and health services who contributed to the delivery of the programme. A number of published models of preventive educational programmes were used to inform the design. These included materials produced in Sandwell (Sandwell Against Domestic Violence Project, 2000), Hackney (Morley, 1999) and by the Zero Tolerance Trust (Zero Tolerance Charitable Trust, 1999).

The workshops that followed the play were designed to raise and promote awareness around issues and concepts such as self-esteem, self-image and respect; cultural and social influences on male and female identities; traditional gender roles and the effects of these on relationships. The programme focused on encouraging exploration of similarities and differences between boys and girls, with some emphasis on how gender is constructed. The workshops also provided the 
opportunity for guided discussion around expectations of male and female behaviour in couples in relationships.

The first workshop was delivered by members of the theatre company immediately following the performance. The researchers attended the performance and the first workshop but did not participate in any way. Five subsequent workshops were delivered on a weekly basis by a school nurse, a youth worker and a domestic violence project worker. One teacher from the school was present at all times to supervise pupils and join in when appropriate. All the staff involved in these workshops were female. Each workshop lasted approximately one hour and began with a class 'warm-up' activity such as throwing the ball to each other while trying to remember each other's names. The sessions ended with a 'wind-down' activity such as a quiz or 'what I have learned today', and pupils finished by completing an evaluation form for the morning's session. Workshop materials were made available to the researchers.

Approximately 85 Year 8 pupils watched the play, which featured a 12-year-old boy and his parents in a domestic setting where the father was abusive and violent towards his partner and son. The pupils then took part in the follow-up workshops. Year 8 pupils were targeted for the programme as this age group was considered to offer the opportunity to intervene with children before they became heavily involved in relationships.

\section{Methodology}

The independent university-based researchers designed a three-stage longitudinal survey. The first questionnaire was administered by teachers and completed in school by all Year 8 pupils one week before the drama performance. It included open-ended and closed questions and was designed to assess pupils' existing knowledge and understandings of domestic violence and attitudes towards domestic violence and relationships in general. All responses were anonymous and participants were reassured that teachers would not be able to identify respondents. At the end of the final workshop, pupils completed the second stage of the survey, which again consisted of both open-ended and closed questions. This questionnaire aimed to discover whether knowledge and understandings of domestic violence had changed, and, if so, in what ways. It was also designed to assess whether pupils' attitudes towards domestic violence and relationships in general had changed and what the participants felt they had learned from the programme.

In addition to the survey, a series of small friendship discussion groups was carried out at stage two of the evaluation, with pupils who volunteered to offer their views and opinions of the programme. Four groups involving a total of 13 pupils (six girls and seven boys) were held. Discussions lasted approximately one hour and focused primarily on pupils' own thoughts and feelings concerning both the play and the workshops. Discussions were tape-recorded but participants were assured of anonymity.

Responses from the closed questions included in the first two stages of the survey were collated and compared. These provided a general picture from which changes 
in attitudes and understanding could be identified. Responses from open-ended questions that appeared in both questionnaires were also compared, and are discussed in more detail later along with data from the friendship group discussions. The first two stages of the evaluation measured the immediate impact of the programme. The extent to which effects had been sustained over time was explored through the third stage of the survey, which was administered one year after the end of the programme. Some early findings from this stage of the survey are included. However, it needs to be acknowledged that, due to practical difficulties encountered in distributing the third questionnaire, only 55 of the original 85 pupils completed this final stage of the evaluation.

\section{Findings}

\section{Knowledge and understandings of domestic violence}

Pupils' understandings of the term 'domestic violence' were examined at each stage of the evaluation. The evaluation showed a distinct shift in pupils' definition of the term domestic violence. Prior to the programme, only one-quarter of the pupils $(27 \%)$ saw domestic violence as violence that was located in the family. This level of understanding of domestic violence appears characteristic of young people generally: Mullender et al.'s (2002) survey of 700 secondary school pupils found that only $28 \%$ identified domestic violence as violence involving their parents or adults at home. Immediately following the programme, just over one-half of the pupils $(51 \%)$ in our study defined domestic violence as a family problem. The proportion who defined domestic violence as something that happened in families had therefore almost doubled. This increase in the pupils' understandings was sustained when the group was surveyed a year after the programme, with $53 \%$ of pupils locating domestic violence in the context of family life. This indicates that the programme was successful in enhancing understanding in the longer term.

Prior to the programme, $28 \%$ of the pupils did not know or did not comment on the statement 'domestic violence is not an issue for people my age'. This proportion fell to $15 \%$ immediately after the programme, with an increase from $41 \%$ to $51 \%$ in those who disagreed with the statement. At the outset of the programme, the vast majority of the young people did not believe that domestic violence only happened on television. This proportion increased slightly immediately following the programme, as did the proportion who agreed that domestic violence is more common than people think, which rose from $82 \%$ to $88 \%$. However, more significantly, by the second stage of the evaluation, the proportion who thought that domestic violence was mostly about men bullying women had more than doubled.

The proportion of those who thought that domestic violence involved women bullying men increased between the first two survey points from $38 \%$ to $46 \%$, with both boys and girls accounting for this rise. The proportion of 'don't know' or not answered responses to this question also increased slightly, suggesting that uncertainly on this issue was greater. This uncertainty was particularly apparent among girls immediately after the programme, perhaps reflecting both the 


\section{F. Bell and N. Stanley}

complexity of the question and the way in which it was phrased in the questionnaire. This complexity might have resided in the difficulty of addressing two issues simultaneously; that is, do women bully men, and does this constitute domestic violence?

The dilemma posed by the question was expressed by one female discussion group member who was unsure about the gendered nature of domestic violence:

About maybe a woman doing it 'cos it's not always just men who do it. I think its men

doing the most to women, but women can probably do it to men as well. (A)

Finally, there was a slight increase immediately after the programme in the proportion of young people who thought that the statement 'domestic violence only happens to people who deserve it' was false. There was evidence from the second stage of the survey that some of the pupils had developed their understandings about the nature of domestic violence as a direct result of the programme. For example, in response to the question 'Did the play change any of your ideas about domestic violence? And in what ways?', these two girls wrote:

I realised it is a big issue.

The fact that people do get bullied when at home but we don't realise if it doesn't happen to us.

One boy wrote:

I thought that domestic violence was just violence.

Despite some uncertainty about gender issues already noted, some pupils had begun to develop a gendered understanding of domestic violence by the second stage of the evaluation. These discussion group participants had clearly picked up on the traditional patriarchal nature of the family relationships depicted in the play, where control and power were firmly placed with the 'dominant' male in the house and the role of the female was visibly subservient:

I remember most the dad was real strict and he wouldn't let them do anything.

He wouldn't let his wife get a job or anything because he said he was the one getting the money-the food on the table.

I remember the part where the dad and son was fighting and the mum tried to split them up and she didn't want any trouble.

The mam used to be soft on the boy but the dad used to be real strict.

And the dad normally punched his wife. (Discussion Group 4, three girls)

When the boys in one of the discussion groups were asked what they might say to the father in the play, their responses demonstrated a fairly sophisticated understanding of inequality, power and control in abusive relationships:

Talk to them. 'Cos some blokes only listen to other blokes.

Some men only listen to other men. They just think women are ... just there.

Some men might just think they can rule. Some of them like to get their own way.

(Discussion Group 3, three boys). 


\section{Seeking help}

Pupils were asked who they would talk to if someone they were close to was experiencing domestic violence. Immediately following the Healthy Relationships programme, the young people were significantly more likely to say that they would talk to family members. The proportion who said that they would talk to their grandparents about domestic violence doubled between the first two survey points, while four times as many children said that they would talk to other family members about domestic violence immediately after participating in the programme.

Prior to the programme, $30 \%$ reported that they would think of talking to the police if someone in their family or someone they knew was experiencing domestic violence, and $10 \%$ said that they would think of talking to social services. Immediately following the programme, these figures were almost halved, with $17 \%$ suggesting that they would think of talking to the police and $6 \%$ proposing talking to social services. A readiness to confide in professionals was replaced by an interest in turning to parents, grandparents and other family members. This finding suggests that the young people who participated in the programme had developed a more realistic approach to seeking advice and help for domestic violence by the second stage of the survey, which involved them turning to known and accessible sources of support rather than anonymous and probably less easy to access 'authority figures'.

The young people participating in the discussion groups identified a range of different people who they would talk to about domestic violence. Confidentiality emerged as an important factor in disclosure. This was mentioned by several pupils, as were sensitivity and understanding in confidantes:

My Grandma. Family or something. 'Cos if I've got a secret that I don't want to tell my mam, my Grandma always sticks up for me and she never tells. (Girl)

He would have taken the advice and phoned the national child helpline. You don't have to give them your name or anything. (Boy)

When participants were asked who they thought they could talk to in their school about issues such as these, there was some ambiguity around talking to teachers:

The teachers, they all, like, some of them are mates and when, like, they go in the staff room they might tell them and they'll tell someone else.

Then it gets out.

And if one of the kids are earwigging, they could spragg it round even if it wasn't true.

It's not confidential. (Discussion Group 3, three boys)

Finally, as well as identifying the importance of talking to someone who could offer confidentiality, sensitivity and understanding, some pupils stressed the value of talking to people who were perceived to have the power to be able to take action to solve the problem:

Childline.

They can give her information and what to do when they're arguing and fighting. 


\section{F. Bell and N. Stanley}

The school governor. 'Cos they sort out all the problems don't they? (Discussion Group 3, three boys)

During the course of group discussions, many participants expressed a sense of personal agency and control in coping with domestic violence by suggesting ways in which children could take responsibility for action. Some of the boys were critical of the sense of helplessness portrayed by the boy in the play:

I didn't feel sorry for him because he should have done something to help his mam.

Stood up for her or something.

Help her do the dinner.

He should have told someone in the family or smacked him or something.

It might make him to look after his mam or whoever he's staying with more, around the house and that. He should be a lot more helpful.

He could do jobs. (Group Discussion 1, four boys)

Some suggested things that children can do to help:

Even if the parents were arguing they could tell them to go out or go for a walk or something like that.

Do it while they're not there. (Discussion Group 3, three boys)

You could go to the police if you saw it happening. To stop it. (Boy)

\section{Attitudes and beliefs about relationships}

Such comments confirm the importance of children and young people being treated as significant actors rather than passive witnesses in relation to domestic violence. There was considerable evidence that the pupils had developed positive ideas on what constituted a 'healthy relationship' immediately after the programme. Responses to the question ' $M y$ rights in a relationship are ...' showed that the young people had absorbed the emphasis given to equality, non-violence and negotiation in relationships:

... to make sure the man respects me and my ideas - to never take anger out on me and to never make me feel helpless and small. (Girl)

... not hitting your partner and you should talk to her and let her have a say in most things. (Boy)

Listening to each other, both making decisions and getting along. (Boy)

Generally, the proportions of respondents who answered 'don't know' or failed to register a view in response to attitudinal questions about relationships decreased between the first two survey points. The decrease in don't knows/not answered was most evident on questions relating to equality and autonomy in relationships, but there was also a very substantial drop from $23 \%$ to $4 \%$ among those who did not know or did not respond to the statement 'If a girl refuses sex, there are times when it may be okay to make her do it'. Prior to the programme nearly one-quarter of the 
group were unsure whether it was okay to force a girl who refused sex to do it. The proportion of these who disagreed with the statement rose from $62 \%$ to $80 \%$ by the second stage of the survey, with substantial shifts of opinion found among boys and girls, but particularly among boys.

\section{Autonomy in relationships}

Shifts in attitudes between the first two survey points were found in the responses to statements that emphasised the need for equality and autonomy in relationships: the young people were more likely to agree with such statements immediately after the programme.

When the responses from the first two survey points to statements about men's and women's autonomy in relationships were compared, it appeared that girls were generally enthusiastic about autonomy for both sexes in relationships and became more so with the programme. Boys, however, while enthusiastic about autonomy for men, were less consistently enthusiastic about autonomy for women even immediately after the programme, when one-fifth of the boys (more than at the outset) disagreed with the idea that women should have their own friends and activities in relationships. It needs to be acknowledged that the concept of autonomy in relationships will be more familiar to girls through their exposure to girls' magazines. Girls will have rehearsed these issues further in discussion and debate with female friends.

Three-quarters of the young people considered that husbands should not slap their wives in the face. There was little shift in this response between the first two survey points. There was, however, a substantial increase between the two survey points in the proportion of young people who disagreed with the view that, in relationships, people should insist on knowing where their partners were at all times.

On the three statements that depicted women as powerful and/or aggressive, the responses were split by gender with girls being significantly more likely to show a shift towards agreeing with such statements than boys immediately after the programme. Rises were identified at the second stage of the evaluation in the proportions both of those who agreed and of those who disagreed with the statement that women should be able to have their own friends and activities that do not involve their partner. Interestingly, both boys and girls also showed an increase in the proportions who disagreed with this statement between the first two survey points-but overall the proportion of boys who disagreed was larger, with $21 \%$ of boys disagreeing with this immediately after the programme.

Prior to the programme, $77 \%$ of the group thought that both partners should have an equal say about decisions; this proportion increased very slightly immediately following the programme. The proportion who thought that it was acceptable for a wife to slap her husband's face went up from $34 \%$ to $40 \%$ immediately after the programme. This increase was only found among the girls, suggesting that, following the programme, girls were more likely to approve assertive models of female behaviour that could encompass violence. This attitude was evident among some of 


\section{F. Bell and N. Stanley}

the female discussion group participants. When asked what they would say to someone like the mother who was depicted in the play, they replied:

Kick him to the floor!

Keep out of his way if he hits you. Kick his head in. (Group discussion 2, two girls)

Those delivering the programme were aware of this issue and considered ways in which messages about being assertive in exercising rights in a relationship can be delivered without suggesting to girls that they should resort to violence.

The number of young people who did not know whether men should be able to have their own friends and activities without their partner reduced significantly between the first two survey points, and the proportion who agreed that they should went up from $65 \%$ to $78 \%$. The proportion who did not know or responded to the statement that in relationships 'it is usually the other person's fault if one person gets mad' dropped at the second stage of the survey from one-third to $22 \%$, while the proportion who disagreed rose from $43 \%$ to $57 \%$.

\section{Young people's views of the programme}

At the second stage of the survey, nearly one-third of the group felt that the play had changed their ideas about domestic violence. Just under $60 \%$ of the group said that they had learnt something from the workshops, with $27 \%$ saying that they had learnt 'quite a lot or a lot'. While boys were slightly more enthusiastic about the play than girls, girls showed higher levels of satisfaction with the workshops than boys. Forty-seven per cent of boys reported that they had not learned much from the workshops, as compared with $24 \%$ of girls. While $44 \%$ of girls said they had learnt quite a lot or a lot from the workshops, only $18 \%$ of boys reported this level of satisfaction.

Similar views of the programme were expressed at the third stage of the survey one year later. Positive evaluations of the play were more evident, with $43 \%$ of pupils considering that the play had changed their ideas about domestic violence; girls were by now more likely than boys to feel this. Enthusiasm for the workshops remained more widespread among girls, but overall the workshops were rated as valuable by $63 \%$ of all those responding to the third survey.

In the discussion groups held immediately after the programme, the workshops were more popular with girls than with boys, who seemed to prefer the play itself, as articulated by these boys:

The play was better than the workshops. You learnt more from the play.

You could actually see what was going on.

And you don't have to hear, you can see it. When you talk about stuff in lessons, you can watch videos and actually see what's happening. (Discussion Group 1, four boys)

Data from the discussion groups also suggested that the boys had particularly enjoyed the more active elements of the workshops, such as drama and role-play:

We didn't really do much moving. We had to just sit still. 
They was doing a lot of talking but we didn't understand much of it.

It was too complicated.

Too much talking.

They did too much talking. Not enough acting. (Discussion Group 3, three boys)

The one where you had to throw a ball at each other and make the other person tell what they remembered about the play. That was the only fun activity we did. (Discussion Group 3, three boys)

Generally, the workshops were more popular with the girls. These girls also explained that they had enjoyed the role-playing elements of the workshops:

I like discussing stuff.

Yeah I like discussing in the groups. That was the best part I think.

Especially doing about what girls like and boys like and we swapped it over. (Discussion Group 2, two girls).

In the view of the programme coordinator, the gender of the facilitator was a significant factor in determining the young people's response to the workshop run by members of the theatre company. Boys were considered to respond well to the male facilitator in this workshop, whose presence could indicate that it was acceptable for men to engage in discussing feelings and relationships. The use of a male facilitator was also felt to convey the idea that messages concerning equality in relationships were not inconsistent with masculine identity.

\section{Discussion}

Overall, the findings here support much previous research and evaluations of preventive programmes in schools (Taylor-Browne, 2001). The evaluation of this pilot programme provided clear evidence that pupils had developed their understanding of domestic violence to view it as violence located in the family; this increased awareness was sustained over time. Prior to the programme, the study, like Mullender et al.'s (2002) survey, identified considerable confusion about the nature of domestic violence. The enhancement of awareness and understanding is a significant achievement as it allows young people to identify personal experiences as abusive. This is the first stage in the process of identifying behaviour as problematic and avoiding it or seeking help.

In addition, the majority of young people reported that they had learnt something by the second stage of the survey. This positive evaluation was still evident at the third stage of the survey one year later. By the end of the programme, there was evidence that some young people had considered inequality, power and control in abusive relationships, and the emotional impact of domestic violence for those experiencing it. Some young people were able to demonstrate that they had developed positive ideas about 'healthy relationships', encompassing values of equality, negotiation and respect by the second stage of the survey. Again, many of these findings are consistent with previous research (Reid Howie Associates Ltd, 2001). 


\section{F. Bell and N. Stanley}

The programme also appeared to have been successful in encouraging young people to identify and contemplate using realistic and accessible sources of help. Immediately following participation in the programme, the young people shifted from a reliance on anonymous and relatively inaccessible professionals to identifying parents and other family members as sources of help. Views about seeking help appeared to have become more realistic and more likely to be translated into action. This finding supports Mullender et al.'s (1998) argument that young people see themselves as potential social actors. They were able to envisage an active role for themselves in challenging domestic violence and supporting those affected by it. However, early findings from the third stage of the survey suggest that the more realistic approach to sources of help identified at the end of the programme had not been sustained by all pupils.

Finally, the pupils responded positively to the use of drama, both in the stage presentation and as a medium for learning in the workshops. This finding is consistent with Hilton's (2003) research into boys' experience of sex education. Boys were particularly likely to value the dramatic and kinetic aspects of the programme and were less likely to value 'sitting and talking' (see also Hannan, 1996; Blake, 1997; Baker, 1998; Wood, 1998).

While the results of this study identify many positive achievements at the point of completing the educational programme, the extent to which change was sustained over time requires fuller investigation and is discussed elsewhere in other publications (see Bell \& Stanley, 2004). However, the current findings do highlight a number of issues that can be used to inform the development of any such future programmes. The results of this pilot study support the use of drama and theatre in education as an effective educational vehicle for delivering healthy relationship programmes within the Personal Health and Social Education curriculum. Such programmes also need to use a variety of learning techniques and formats if they are to appeal to both sexes. For example, a similar evaluation (Hobbs, 2002) involving the use of puppetry in Sex and Relationships education found that this medium freed pupils to express issues that they would otherwise have found difficult and embarrassing to express publicly.

One of the issues identified by staff delivering the Healthy Relationships programme was the value of a male facilitator, particularly for boys. When boys are being encouraged to challenge stereotypical patterns of male behaviour, it is important that alternative models of masculinity are available. Male facilitators offer a valuable means of engaging boys in territory and discussion traditionally defined as female (see also Morley, 1999). Staff delivering this programme were exclusively female, which may also explain why girls reported overall higher levels of satisfaction than boys at the end of the programme.

Hague et al. (2001) argue that a gendered understanding of domestic violence is essential to the mainstreaming of educational approaches. Although there was some indication in this study that the young people were able to identify and comment on the gendered nature of violence following the programme, there was also evidence of uncertainty for some at this stage of the programme. The finding that boys were less 
enthusiastic than girls about autonomy for women in relationships emphasises the need for a strong focus on gender in the design and delivery of the programme.

The shift towards more polarised views in both boys and girls on statements depicting women as powerful and/or aggressive at the end of the programme provides further evidence to support this argument. Thus, in promoting values of assertion and autonomy for girls, educators delivering such programmes in the future need to recognise the risks of confusing assertion with violence and encouraging young women to mimic traditional male patterns of behaviour. Recent research by Burman et al. (2003), which explored girls' views of violence and violent behaviour, found that $50 \%$ of the girls described the ability to 'stick-up' for oneself in both physically violent and verbally abusive situations as extremely important. Results from this research and the present study would suggest that 'girl power' needs to be deconstructed and carefully analysed for the purposes of healthy relationships programmes, and also in relation to cultural values. Similarly, future programmes need to emphasise responsibilities and caring in relationships in order to balance messages about rights.

There is a pressing need for prevention work to move rapidly towards a consistent mainstream approach. Such an approach needs to retain a focus on gender in the design and delivery of programmes and take account of the wider social context and the different patterns of socialisation for boys and girls. Future programmes may benefit from research that explores in more detail boys' apparent preference for the more kinetic aspects of such programmes and considers its relevance for design and delivery. There is also a need to secure and evaluate the involvement of male facilitators who can convey messages about equality in relationships in a way that is consistent with masculine identity. Without this, there may be a risk of boys reacting defensively to some of the programme content and resisting its core messages.

\section{References}

Avery-Leaf, S., Cascardi, M., O’Leary, K. D. \& Cano, A. (1997) Efficacy of a dating violence prevention program on attitudes justifying aggression, fournal of Adolescent Health, 21, 11-17.

Baker, P. (1998) Sex education in the boy zone, Healthlines, May, 52, 12-13.

Bell, J. \& Stanley, N. (2004) Tackling domestic violence at the local level: an evaluation of the Preston Road Domestic Violence Project (Hull, University of Hull).

Blake, S. (1997) Youth and community settings uncharted territory, in: G. Lenderyou \& C. Ray (Eds) Let's hear it for the boys (London, National Children's Bureau).

Burman, M., Brown, J., Tisdall, K. \& Batchelor, T. (2003) A view from the girls: exploring violence and violent behaviour (Basingstoke, ESRC).

Department of Education and Employment (1999) National healthy schools standard guidance (London, Department of Education and Employment).

Foshee, V., Bauman, K., Arriaga, X., Helms, R., Koch, G. \& Linder, G. (1998) An evaluation of Safe Dates, an adolescent dating violence prevention program, American fournal of Public Health, 88, 45-50.

Hague, G., Kelly, L. \& Mullender, A. (2001) Challenging violence against women (Bristol, Policy Press).

Hannan, G. (1996, April) A bunch of fives sorts out the boys, Times Educational Supplement, p. 190. 


\section{F. Bell and N. Stanley}

Hilton, G. (2003) Listening to the boys: English boys' views on the desirable characteristics of teachers of sex education, Sex Education, 3(1), 33-45.

Hobbs, A. (2002) Sex and relationships education project: final evaluation report (Blackpool, Dynamic New Animation).

Jaffe, P., Suderman, M., Reitzel, D. \& Killip, S. M. (1992) An evaluation of a secondary school primary prevention program on violence in intimate relationships, Violence and Victims, 7, 129-146.

Macgowan, M. (1997) An evaluation of a dating violence prevention program for middle school students, Violence and Victims, 12, 223-235.

Meyer, H. \& Stein, N. (2001) Relationship violence prevention education in schools. What's working, what's getting in the way, and what might be some future directions, paper presented at the $7^{\text {th }}$ International Family Violence Research Conference, Portsmouth, NH.

Morley, R. (1999) Respect: a resource pack for schools challenging violence and abuse-exploring the meaning of respect with 14-16 year olds (London, City and Hackney Community Services NHS Trust).

Mullender, A. (2000) Reducing domestic violence ... what works? Meeting the needs of children, Crime Reduction Research Series (Coventry, University of Warwick).

Mullender, A. (2001) Meeting the needs of children, in: J. Taylor-Browne (Ed.) What works in reducing domestic violence: a comprehensive guide for professionals (London, Whiting and Birch Ltd).

Mullender, A., Debbonaire, T., Hague, G., Kelly, L. \& Malos, E. (1998) Working with children in women's refuges, Child and Family Social Work, 3, 87-98.

Mullender, A., Hague, G., Imarn, V., Kelly, L., Malos, E. \& Regan, L. (2002) Children's perspectives on domestic violence (London, Sage).

Reid Howie Associates Ltd (2001) Evaluation of the zero tolerance 'respect' pilot project: summary report (Edinburgh, Scottish Executive Central Research Unit).

Sandwell Against Domestic Violence Project (2000) Violence free relationships averting rights - a programme for young people (Cradley Heath, SADVP).

Taylor-Browne, J. (Ed.) (2001) What works in reducing domestic violence: a comprehensive guide for professionals (London, Whiting and Birch Ltd).

Wood, A. (1998) Sex education for boys, Health Education, 3, 95-98.

Zero Tolerance Charitable Trust (1999) Respect: a resource pack for schools challenging violence and abuse (Edinburgh, ZTCT). 